\title{
RACIONALIDADE LIMITADA E AGRICULTORES FAMILIARES PRODUTORES DE TABACO NO VALE DO RIO PARDO-RS
}

\author{
BOUNDED RATIONALITY AND FAMILY FARMERS \\ PRODUCING TOBACCO IN THE VALE DO RIO PARDO- \\ RS
}

\author{
Marcelo Moraes de Andrade \\ Universidade Federal do Oeste do Pará - Santarém - PA - Brasil \\ Leonardo Xavier da Silva \\ Universidade Federal do Rio Grande do Sul - Porto Alegre - RS - Brasil
}

\begin{abstract}
Resumo: Este artigo tem por objetivo analisar o processo de racionalidade que sustenta a decisão de agricultores familiares em produzir ou deixar de produzir tabaco. Para tanto, foram entrevistados 63 agricultores na microrregião do Vale do Rio Pardo/RS. Utilizou-se como auxílio analítico a abordagem da racionalidade limitada proposta por Simon (1965). Empregou-se, nesta análise, dados quantitativos e qualitativos. Constatou-se que as condutas dos agricultores são baseadas em normas sociais, culturais e econômicas estabelecidas pelo contexto institucional. As reações dos agricultores frente ao conflito cognitivo causado pelo descontentamento com sua situação atual e as poucas ou inexistentes alternativas de mudanças estão ligadas a elementos estruturais e subjetivos. Os elementos estruturais e subjetivos, a situação atual dos agricultores e seus projetos futuros, suas reações frente à decisão em produzir ou deixar de produzir tabaco são pautadas pela falta de opção, não pela ação da racionalidade limitada. Soma-se ainda carências de organização dos agricultores e informações incompletas sobre o setor produtivo.
\end{abstract}

Palavras-chave: Racionalidade. Produção de tabaco. Agricultura familiar.

Abstract: This article aims to analyze the process of rationality that underpins the decision of farmers of producing or stop producing tobacco. To this end, 63 farmers who live in the micro region of Vale do Rio Pardo/RS were interviewed. The approach of limited rationality proposed by Simon (1965) was used as an analytical aid. It was used in this analysis quantitative and qualitative data. As the results, It was found that the 
conduct of farmers is supported on social, cultural and economic standards established by institutional context. The reactions of farmers before the cognitive conflict caused by dissatisfaction with their current situation and the few or no alternatives for change are linked to structural and subjective elements. The structural and subjective elements, the current situation of farmers and their future projects, their reactions about the decision of producing or stop producing tobacco are guided by lack of choice, not by the action of bounded rationality. Added to this conclusion, the weak organization of the farmers and asymmetric information about the productive sector.

Keywords: Rationality. Tobacco production. Family farming.

\section{INTRODUÇÃO}

As polêmicas em torno da produção e consumo do tabaco têm exigido da sociedade novas concepções e a necessidade de diálogos mais abrangentes sobre os paradigmas que sustentam o setor tabagista. Ponderar sobre os problemas históricos relacionados à produção e comercialização do tabaco implica em refletir sobre o funcionamento de um setor produtivo deveras centralizador e contraditório, o que requer a análise dos anseios e da racionalidade dos agricultores inseridos na cadeia de produção.

No Brasil, em anos recentes, o questionamento por parte dos agricultores familiares produtores de tabaco sobre seu bem-estar e condição socioeconômica, marcada pela falta de autonomia e de alternativas de renda, tem comprometido as relações dos agentes e posto em xeque o papel que as famílias exercem no desenvolvimento econômico e social do setor. Sendo o Brasil o segundo maior produtor mundial de tabaco e o primeiro em quantidade exportada, essa discussão torna-se importante para o país, uma vez que parcela significativa de famílias dedicam-se a esta atividade.

No cenário nacional, os três estados da região Sul do Brasil (Paraná, Santa Catarina e Rio Grande do Sul) destacam-se na produção de tabaco. A produção de tabaco desenvolvida nessa região funciona por meio do Sistema Integrado de Produção de Tabaco - SIPT, onde os dois principais componentes desse sistema são os agricultores familiares e as agroindústrias (PRIEB, 2005). Esse setor opera por meio de características específicas, "[...] cuja marca central é o elevado controle das empresas agroindustriais que não se limitam à 
concentração da produção no âmbito da comercialização e processamento, mas também atuam enquanto fornecedores dos principais insumos [...]" do processo de produção (PRIEB, 2005, p. 38).

O SIPT tem se mostrado um eficiente mecanismo de inserção de agricultores a um mercado globalizado, além de oferecer várias garantias aos integrados, tais como assistência técnica, fornecimento de insumos, garantia de compra do produto etc. A eficiência do SIPT se manifesta também à medida que consegue deixar bem evidente para os agricultores as consequências de sua recusa à integração. Ao passo que, para os agricultores, as consequências de se adotar outro cultivo são incertas, por envolverem fatores que escapam ao seu domínio (tecnologia necessária, mercado, preço etc.). Em virtude disso, a matriz institucional criada pelo SIPT é responsável por determinar as consequências que os agricultores podem antever, assim como as que ele não preverá.

Nesse sentido, os agricultores familiares sofrem pressão de várias formas. Seu conhecimento da realidade do setor produtivo do tabaco como um todo é fragmentado, seu tempo para buscar e avaliar alternativas é limitado. Sabe-se que, em geral, os aspectos pessoais dos agricultores influenciam suas decisões, bem como o ambiente organizacional no qual estão inseridos, e esses, consequentemente, os resultados econômicos de suas propriedades (CANZIANI, 2001). Porém, é um exercício que requer análise dos anseios e da racionalidade dos agricultores inseridos na cadeia de produção.

Na microrregião do Vale do Rio Pardo - VRP, no Estado do Rio Grande do Sul, o complexo fumageiro constitui o maior polo industrial de tabaco do mundo. Porém, a relação entre agricultores e agroindústrias é permeada de conflitos em relação aos rendimentos dos agricultores, à intermediação da indústria na obtenção de créditos para a produção, assim como na definição da representatividade dos fumicultores nos fóruns que negociam os preços pagos pelo tabaco em cada safra. Além disso, os atores da microrregião do VRP começam a se questionar sobre a sustentabilidade da produção de tabaco, motivados por campanhas e medidas nacionais e internacionais de combate ao tabagismo.

Contudo, a produção de tabaco segue sendo uma alternativa aos agricultores do VRP, o que torna importante entender a racionalidade da 
decisão dos mesmos em escolher essa atividade agrícola, apesar desse cenário conflituoso. Nesse sentido, denota-se que analisar uma decisão é pensar sobre um dos aspectos mais significativos da vida (PEREIRA; FONSECA, 1997).

É notório que a produção de tabaco, na grande maioria dos casos, é uma atividade que se reproduz de pai para filho, assim, a referência dos agricultores para suas escolhas são seus pais e sua própria experiência, uma vez que começam a trabalhar ainda na infância. Desse modo, a cultura e a experiência dos agricultores formam o universo de suas escolhas, é por meio delas que ele cria seu sistema de valores, crenças e regras elementares.

Considerando esses fatores, questiona-se se a opção dos agricultores em produzir ou deixar de produzir tabaco é uma ação reflexa, condicionada por seu contexto (terra escassa, pouco recurso financeiro, pouca informação e falta de alternativas disponíveis), ou se é produto de sua racionalidade, planejamento e projeção para o futuro. Apesar da pertinência de tal questionamento, faltam informações e análises suficientes sobre o comportamento e a racionalidade dos agricultores familiares produtores de tabaco. Tendo isso em conta, a opção por produzir tabaco é uma escolha ou uma falta de escolhas? Sendo uma escolha, quais as variáveis que influenciam diretamente a opção dos agricultores?

Estudos como os de Simon (1965), Williamson (1985), North (1994), Silva (2002) têm demonstrado que a compreensão do comportamento e das escolhas dos agentes é fundamental para o entendimento do modo como o sistema econômico é organizado e desenvolvido. Nesse processo, as estratégias dos atores sociais merece destaque, uma vez que é a partir delas que irão emergir a diversidade e heterogeneidade dos territórios (SCHNEIDER, 2004). Reportando-se a Schneider (2004), o autor constata que atualmente há uma necessidade crescente dos estudos sobre o rural e sobre desenvolvimento territorial abarcarem novas referências e orientações que sejam capazes de englobar as diversas transformações da sociedade.

No âmbito dessas discussões, há carência de estudos que avaliem o impacto psicológico de políticas públicas sobre o contentamento ou descontentamento desses agricultores com suas atividades, sobre aspectos de liderança, na área de organização do trabalho, sobre 
cooperativismo e associativismo, sobre transferência de tecnologia, saúde mental e bem-estar psicológico de agricultores familiares produtores de tabaco. Muitas entidades se dedicam a avaliar dados econômicos, deixando de lado questões de ordem subjetiva, tais como a opção por uma prática agrícola em detrimento de outra.

Em vista desse contexto, o objetivo deste trabalho é analisar a racionalidade da tomada de decisão de agricultores familiares do VRP em produzir ou deixar de produzir tabaco. De forma específica, objetiva-se verificar o interesse dos agricultores em seguir ou não na produção de tabaco, identificar e analisar os fatores que orientam a tomada de decisão dos mesmos.

Parte-se do pressuposto de que as decisões são restritas ou influenciadas pelas limitações do ser humano no acesso à informação (em decorrência de problemas de custo e tempo) e em processar cognitivamente todas as opções, devido às crenças, conflitos e jogos de poder que estão envolvidos na situação (SIMON, 1965). Para tanto, esta análise se inspira nos trabalhos sobre racionalidade de Simon (1965; 1972) e toma-o como ponto de partida e eixo norteador da análise.

Considera-se que este estudo corrobora com a problematização da relação entre dinâmica agrícola e desenvolvimento do território, uma vez que aborda o comportamento dos agricultores, atores que sustentam a produção de tabaco. De acordo com Schejtman e Berdegué (2004), um dos obstáculos para a superação da pobreza e para a promoção do desenvolvimento territorial reside no fato de que uma parcela significativa de pequenos e médios agricultores convivem diariamente com a incerteza. Soma-se a isso um ambiente que requer constante inovação para se atingir a competitividade, estando eles condicionados ao acesso limitado à terra e à informação, pouca tecnologia, falta de instrumentos de gestão adequados, água e recursos financeiros insuficientes (SCHEJTMAN; BERDEGUÉ, 2004).

$\mathrm{O}$ artigo está dividido em cinco partes, além desta introdução. Em seguida, apresenta-se a metodologia utilizada na pesquisa. Na terceira parte, expõem-se o referencial teórico utilizado na análise. Na quarta, é feita uma breve discussão sobre a produção de tabaco no VRP. Posteriormente, são apresentados e discutidos os elementos constituintes da racionalidade dos agricultores. Por fim, na seção final, efetua-se algumas considerações finais. 


\section{METODOLOGIA}

A construção desta pesquisa é fundamentada em pesquisa empírica de cunho qualitativo e quantitativo. A unidade de análise deste trabalho são agricultores familiares cuja trajetória de vida tem relação com a produção de tabaco. A amostragem da pesquisa caracteriza-se como do tipo intencional estratificada não proporcional.

O local escolhido para a realização deste estudo foi a microrregião do Vale do Rio Pardo - VRP, no Rio Grande do Sul. A escolha desta microrregião justifica-se por sua relevância para o setor produtivo do tabaco no país, uma vez que a microrregião como um todo possui uma forte relação histórica com a produção, processamento, comercialização e exportação de tabaco (SILVEIRA, 2007). Na Tabela 1, a seguir, pode-se observar os municípios contemplados na pesquisa, o número de entrevistas por município, bem como a quantidade de entrevistas por estrato da amostra. 
Tabela 1. Distribuição das entrevistas de acordo com os municípios e por categoria de agricultor no VRP (2013)

\begin{tabular}{|c|c|c|c|c|c|}
\hline \multirow{3}{*}{ Municípios } & \multirow{3}{*}{$\begin{array}{l}\text { Número } \\
\text { de } \\
\text { entrevist } \\
\text { as }\end{array}$} & \multicolumn{4}{|c|}{ Agricultores } \\
\hline & & \multicolumn{2}{|c|}{ Produtores de tabaco } & \multicolumn{2}{|c|}{ Ex-produtores de tabaco } \\
\hline & & $\begin{array}{c}\text { Especializad } \\
\text { os }\end{array}$ & $\begin{array}{c}\text { Diversificad } \\
\text { os }\end{array}$ & $\begin{array}{c}\text { Substituíra } \\
\mathrm{m}\end{array}$ & Abandonaram \\
\hline $\begin{array}{c}\text { Santa Cruz do } \\
\text { Sul }\end{array}$ & 14 & 11 & 1 & 1 & 1 \\
\hline Venâncio Aires & 18 & 11 & 4 & 2 & 1 \\
\hline Sinimbu & 2 & 1 & 1 & - & - \\
\hline Vera Cruz & 3 & 1 & 2 & - & - \\
\hline Vale do Sol & 1 & - & 1 & - & - \\
\hline Herveiras & 4 & - & 4 & - & - \\
\hline Rio Pardo & 21 & 2 & 10 & 5 & 4 \\
\hline TOTAL & 63 & 26 & 23 & 8 & 6 \\
\hline
\end{tabular}

Fonte: Elaborado pelo autor a partir de dados da pesquisa de campo.

Para geração de banco de dados, foram utilizadas fontes primárias e secundárias. Para a coleta de dados junto aos agricultores, empregouse a entrevista como fonte elementar de informações. As entrevistas foram conduzidas com apoio de um questionário semiestruturado, combinando perguntas fechadas e abertas.

Em relação aos agricultores especializados e diversificados, cabe destacar que, para o Instituto Brasileiro de Geografia e Estatísticas IBGE (2006), um estabelecimento é considerado especializado se o valor da produção do principal produto agrícola ultrapassar $66 \%$ do valor total de produção do estabelecimento. Como esta pesquisa não contemplou análises de dados econômicos dos entrevistados, o critério adotado para definir um agricultor especializado foi produzir somente tabaco para comercialização. Tendo em vista que todas as famílias entrevistadas afirmam cultivar diversos alimentos para o autoconsumo, o fator determinante para a diferenciação entre agricultores diversificados ou não diversificados foi a prática de outra atividade de produção voltada à comercialização.

Os dados foram analisados a partir da análise de conteúdo (qualitativa) e estatística descritiva (quantitativa). A análise de conteúdo atua sobre a fala, ela descreve, analisa e interpreta as mensagens de todas as formas de discurso, procurando ver o que está por trás das palavras. Busca indicadores (quantitativos ou não) que permitam a 
inferência de conhecimentos relativos às condições de produção (variáveis inferidas) destas mensagens (BARDIN, 2011). Nesse ponto de vista, o conteúdo da comunicação demonstra-se rico e apresenta uma visão polissêmica e valiosa, que, notadamente, permite ao pesquisador qualitativo uma variedade de interpretações (CAMPOS, 2004).

Tendo em vista a conclusão de Simon (1965) de que a racionalidade depende do contexto e é limitada por ele, entende-se que é o processo de percepção que transforma a realidade em um padrão que os agentes possam reconhecer. Nesse sentido, valendo-se da análise de conteúdo das falas dos agricultores, constatou-se, entre os entrevistados, duas percepções em relação ao cultivo do tabaco, uma negativa e outra positiva:

a) percepção negativa do cultivo do tabaco: constituída por agricultores descontentes com a atividade, no campo da produção reclamam da intensidade do trabalho, do risco à saúde pelo uso de agrotóxicos, do custo da mão de obra e de sua gradual diminuição, dos altos custos de produção; na parte comercial apontam os baixos preços pagos pelo fumo e o pouco poder de barganha nas negociações;

b) percepção positiva do cultivo do tabaco: agricultores que identificam nessa atividade pontos positivos e negativos, como outra qualquer, demonstram gratidão com a atividade, tendo ela importância na geração de renda e assegurar sua permanência no meio rural.

Tendo em vista os estudos de Campos (2004), as duas percepções apresentadas acima representam uma tentativa de trazer os resultados dos conteúdos manifestos (explícitos) para o campo da objetivação. Destarte, buscou-se identificar tanto os "conteúdos manifestos" quanto os "conteúdos latentes" nas falas dos agricultores.

\section{PROCESSO DE DECISÃO E RACIONALIDADE}

Muitos autores abordam, em seus estudos o termo "racionalidade" (SEN, 1999; SMITH, 2010, SIMON, 1965; WILLIAMSON, 1985), entre outros. As definições permitem uma diversidade de interpretações do 
termo e, sobretudo, de sua interação com a administração e a economia.

Para Chiavenato (2000), é possível distinguir dois modos de comportamento: o cognitivo, baseado na racionalidade, na lógica, no uso da mente e da inteligência; e o afetivo, baseado nos sentimentos, nas emoções e na afetividade. Do ponto de vista teórico, há diversas maneiras de estudar o processo decisório. Porém, a Teoria da Escolha Racional e a Teoria da Decisão são as mais destacadas. A primeira se preocupa em estudar e prever padrões de comportamentos e a segunda tem características normativas e busca informar o que um agente faria se fosse racional (BAERT, 1997).

No âmbito do processo decisório, as interpretações diferem de acordo com a intenção explicativa, incluindo os aspectos racionais, organizacionais, políticos, psicológicos e intuitivos (ANDRADE, 2010). Para Chiavenato (2000, p. 416) "decisão é o processo de análise e escolha entre as alternativas disponíveis de cursos de ação que a pessoa deverá seguir".

Toda escolha é significativamente influenciada pelas características estruturais da pessoa que decide (inteligência, status social, sexo, cultura, crenças, motivações, auto-organização, saúde, dinheiro etc.) e por seu estado emocional no momento da escolha (PEREIRA; FONSECA, 1997). Em vista disso, ao decidir, o indivíduo deve entender as causas de sua opção, numa tentativa de justificar para si próprio o motivo pelo qual está agindo de determinada maneira. Tal justificativa é entendida como uma avaliação que o orienta para discernir.

Para Simon (1965, p. 283), do ponto de vista do indivíduo, uma decisão é racional, "[...] se for congruente com os valores, as alternativas e as informações que considerou ao tomá-la". Porém, é impossível que o indivíduo conheça todas as alternativas e consequências de uma escolha (SIMON, 1965). O agente não alcança a maximização da racionalidade (racionalidade objetiva $=$ melhor escolha), pelo fato de ser limitado e influenciado, principalmente, por fatores que escapam ao domínio do seu consciente: destreza manual, o tempo de reação ou força física, rapidez de seus processos mentais, por seus conhecimentos matemáticos, por seus valores e assim por diante. 
$\mathrm{Na}$ perspectiva de March e Simon (1970), a teoria da escolha racional incorpora duas características fundamentais: a) a escolha sempre é feita em função de um modelo da situação real, restrito, aproximado e simplificado. Esse modelo representa a definição da situação, por parte da pessoa que faz a escolha; b) os elementos da definição da situação não são dados - isto é, não os tomamos por pressupostos de nossa teoria -, mas constituem o produto de processos psicológicos e sociológicos que incluem as atividades da pessoa que faz a escolha e as de outros integrantes do ambiente (MARCH; SIMON, 1970).

\subsection{A concepção de racionalidade limitada e o homem administrativo}

Considerando as limitações do agente em obter todas as informações, ele contenta-se em adquirir um número limitado, "um nível satisfatório", que possibilite a identificação dos problemas e algumas soluções alternativas (ZYLBERSZTAJN, 1995). Desse modo, "[...] o que o indivíduo faz, na realidade, é formar uma série de expectativas das consequências futuras, que se baseiam em relações empíricas já conhecidas e sobre informações acerca da situação existente" (SIMON, 1965, p.81).

Para Simon, a racionalidade não é uma orientação objetiva frente à realidade, mas uma direção subjetiva baseada na informação incompleta que os indivíduos detêm. O agente comporta-se racionalmente de acordo com um modelo cognitivo simplificado (CARVALHO, 2008). Conforme Simon (1965, p. 89), "[...] a racionalidade ocupa-se da seleção de alternativas de comportamento preferidas de acordo com algum sistema de valores que permite avaliar as consequências desse comportamento".

Nesse sentido, a governança dos sistemas agroindustriais é construída de modo a prover os mecanismos de incentivo e controle dos agentes que atuam dentro do sistema (ZYLBERSZTAJN, 1995). Tais mecanismos precisam ser previsíveis, de modo que seja possível poupar a racionalidade dos responsáveis pelas definições das ações.

Todo processo decisório humano ocupa-se da descoberta e seleção de alternativas satisfatórias, somente em casos excepcionais preocupa-se com a descoberta e seleção de alternativas ótimas (MARCH; 
SIMON, 1970). Simon caracteriza a conduta de satisfação como um mecanismo de escolha em que o indivíduo planeja somente sequências curtas de decisões (CARVALHO, 2008).

O homem administrativo considera o mundo como sendo "[...] vazio e ignora a inter-relação de todas as coisas (cuja observância é tão paralisadora para o pensamento e para a ação), assim, ele é capaz de tomar decisões guiadas por regras empíricas simples, que não sobrecarregam sua capacidade de pensar" (SIMON, 1965, p. 29). Na opinião de Simon, não existe uma decisão correta, mas uma escolha adequada a um determinado momento, pois nada é completo ou perfeito em um ambiente mutável.

O homem administrativo, sendo um ser que se satisfaz, que se contenta, não precisa do máximo absoluto, mas, sim, do suficiente para se contentar dentro das possibilidades da situação. Está orientado para satisfazer as necessidades que estão ao seu alcance devido aos limites da racionalidade (que é limitada).

Para a busca de solução de problemas capazes de proporcionar alternativas e consequências adequadas, é preciso que se decida primeiro qual o critério que vai governar a escolha. Uma alternativa será satisfatória quando: a) houver padrões que estabeleçam os requisitos mínimos de uma alternativa satisfatória; b) a alternativa em causa preencher ou exceder todos esses requisitos mínimos (MARCH; SIMON, 1970).

A complexidade do comportamento humano torna praticamente interminável a busca de explicações sobre sua motivação. As pessoas são motivadas por inúmeras causas, em diferentes circunstâncias (MAXIMIANO, 2007). Além disso, dado o contexto social incerto, as necessidades humanas são ávidas, o que acarreta apatia dos indivíduos a partir de determinado ponto (CARVALHO, 2008).

Os processos de percepção das situações e o raciocínio são básicos para a explicação do comportamento humano: o que uma pessoa aprecia e deseja influencia o que vê e interpreta, assim como o que vê e interpreta influencia o que ela aprecia e deseja. Em outros termos, a pessoa decide em função de sua percepção das situações (CHIAVENATO, 2000). 


\section{A PRODUÇÃO DE TABACO NO VALE DO RIO PARDO/RS}

Na concepção de Lamarche (1993, p. 15), a agricultura familiar "[...] corresponde a uma unidade de produção agrícola onde propriedade e trabalho estão intimamente ligados à família". O fato de uma estrutura produtiva associar família-produção-trabalho tem consequências fundamentais para a forma como ela age econômica e socialmente (WANDERLEY, 1999). Nesse sentido, para Lamarche (1993), a análise dessa categoria de agricultores deve centrar-se em dois níveis: a) no modelo de funcionamento e; b) em uma classe social no interior desse modelo.

O cultivo de tabaco na microrregião do VRP é resultado histórico da combinação entre uma forma industrial com a utilização de trabalho assalariado, e outra, agrícola, vinculada ao trabalho familiar. No processo de evolução dessa prática agrícola a colonização alemã teve participação decisiva (PRIEB, 2005).

$\mathrm{Na}$ análise de Etges (1989), a expansão e a intensificação da fumicultura no Rio Grande do Sul deu-se nas regiões de pequenas propriedades de produção familiar, em virtude, principalmente, dos locais onde estão instaladas serem inaptos para cultivo de outras culturas, como a soja, o trigo e a pecuária extensiva. Somam-se a esses fatores, os solos ruins. Os principais fatores que fizeram da microrregião do VRP um polo de produção de tabaco mundial estão associados à biodiversidade da mata atlântica. O clima moderado e chuvas bem distribuídas ao longo das estações, concorrem para que seja produzido o melhor fumo de estufa do mundo (NEVES, 2010).

Pode-se dividir as transformações na produção de tabaco da microrregião do VRP em dois períodos distintos, de acordo com Prieb (2005): o primeiro é o anterior à década de 1960, marcado pela presença majoritária do capital nacional no setor e; o segundo período, posterior a 1970, caracterizado pela consolidação do setor, com centralização e desnacionalização do parque industrial. Para a autora, as transformações foram acompanhadas de mudanças na produção de tabaco, onde a forma artesanal deu lugar à modernização do processo de trabalho do fumicultor (PRIEB, 2005). O circuito de atrelamento compulsório de cada agricultor com as indústrias processadoras de tabaco ampliou-se durante o séc. XX, tornando-se internacional e 
submetido aos critérios que impõem a redução de custos e a qualidade do produto como vantagens comparativas (FERREIRA, 2006).

De acordo com Silva et al. (2013), 76,5\% da produção de tabaco no Sul do Brasil é praticado em estabelecimentos de até 20 ha. Esse dado evidencia a forte inserção da agricultura familiar na atividade fumicultora, especialmente, a partir de dois aspectos característicos desses agricultores: o uso intensivo de mão de obra familiar e a organização da produção que associa a produção para autoconsumo e para o mercado, neste caso o tabaco.

A produção de tabaco está sujeita, na grande maioria dos casos, a um contrato, cujos termos referentes à produção e organização do cultivo são determinados pelas empresas. O volume, estabilidade e a qualidade da produção são controlados pelos dispositivos do SIPT. Na opinião de Rudnicki (2012, p. 44-45), o contrato passa a ser "[...] um instrumento de controle que objetiva mitigar ou enfrentar possíveis comportamentos oportunistas e reporta os atores a uma situação de não negociação perante as empresas".

\subsection{Conflitos e contradições na produção de tabaco no Vale do Rio Pardo}

Os reflexos das transformações ocorridas no cenário mundial do tabaco têm conduzido, no Brasil, as relações profissionais e as famílias agricultoras a dificuldades de vários tipos (PRIEB, 2005), cujas soluções os agricultores percebem que estão além de seu controle e possibilidade de manejo. Soma-se a isso o fato de que as decisões mais importantes e impactantes do setor são tomadas pelas indústrias processadoras. São as indústrias, agindo sob a lógica de mecanismos do mercado internacional, tanto da matéria-prima quanto do produto industrializado, que exercem pressão sobre o Estado em favor de seus interesses.

Dessa forma, a produção de tabaco, assim como possui a capacidade de dinamizar toda a economia de um setor, da mesma forma consegue gerar muitas controvérsias. As principais questões ligadas a esta atividade estão relacionadas aos seguintes fatores: o tabagismo, com o qual são gastos boa parte dos recursos recolhidos por meio dos impostos; o uso intensivo de defensivos agrícolas; impactos ambientais 
devido ao uso de agrotóxicos e desmatamentos em algumas regiões; empobrecimento e endividamento das famílias; penosidade do trabalho, uma vez que o sistema de produção exige mão de obra intensiva (ZOTTI, 2010). Esses itens aparecem como desafios a serem enfrentados e superados pelo setor.

Em vista disso, observa-se que há certo desequilíbrio nas relações estabelecidas entre os principais agentes do setor, agricultores familiares e agroindústria, uma vez que esta disputa se dá entre dois agentes desiguais. De um lado está o oligopsônio (SILVA, 2002), formado pelas empresas multinacionais de tabaco, com controle total, tanto em nível nacional como internacional, sobre o mercado da matéria-prima. E de outro lado, os agricultores, com entidades legitimamente constituídas para representá-los na defesa de seus interesses, mas que possuem pouco poder de barganha (ETGES, 1989).

Assim, esse sistema parece operar sob os pilares do que caracteriza o próprio subdesenvolvimento, que, para Abramovay (2001, p. 5), são um conjunto de instituições, ou seja, as regras do jogo, as "[...] normas e valores que orientam a conduta do dia a dia, de orientações que reduzem a incerteza dos indivíduos - que dissociam o trabalho do conhecimento, que dificultam o acesso à terra e que bloqueiam a inovação". Nesse cenário, "[...] as organizações que emergem deste quadro institucional são altamente eficientes em sua capacidade de inibir o aparecimento dos potenciais produtivos da sociedade e de dificultar as formas não hierárquicas de cooperação em que se pode fundamentar" (ABRAMOVAY, 2001, p. 5) o desenvolvimento.

Ademais, o que mais atinge as famílias de agricultores são os fatores que as tornam submetidas a esse cenário de megaempresas: altos níveis de lucratividade, trabalho duríssimo, vigilância severa e posição subalterna nas negociações que Ihes dizem respeito (FERREIRA, 2006). Nesse circuito, os ganhos no comércio internacional estão longe de serem partilhados com as famílias de agricultores.

\section{A RACIONALIDADE DOS AGRICULTORES: CONECTANDO ELEMENTOS SUBJETIVOS E ESTRUTURAIS}


Na perspectiva de Lima et al. (2001, p. 70), na avaliação do comportamento de agricultores familiares, deve-se considerar que "[...] há uma dupla adaptação entre a situação e objetivo. A situação depende dos objetivos do agricultor e os objetivos dependem da situação". Desse modo, no processo de decisão dos agricultores, estão presentes diversos elementos relacionados a fatores internos e externos, porém, enquanto uns apresentam mais peso que outros, muitos são ignorados.

Consoante a isso, constatou-se que os fatores que influenciam a racionalidade da decisão dos agricultores entrevistados no VRP em produzir ou deixar de produzir tabaco podem ser agrupados em dois conjuntos de elementos de grande importância e que estão presentes de maneira estreita em seu comportamento. Esses elementos são os principais termos de referência dos agricultores, sendo eles:

a) elementos estruturais: constituído pelas relações sociais (família) e forças produtivas (forte peso da mão de obra familiar e da estrutura fundiária) (ABRAMOVAY, 1992) e o ambiente institucional, constituído, principalmente, pelas garantias do SIPT;

b) elementos subjetivos: constituído pelas características individuais de cada agricultor, como a inteligência, conhecimento, crenças, valores, motivações, saúde, tradições culturais, estado emocional, memória do passado, ambição, satisfação individual.

Conforme demonstrado no Gráfico 1 a seguir, as interações entre os elementos estruturais e subjetivos de cada categoria de agricultores formam redes de conexões complexas que variam de intensidade de acordo com sua influência na construção da percepção e posterior reação dos agricultores. Sendo assim, é a proporção ou a intensidade desses elementos que irão definir a racionalidade dos agricultores na decisão entre produzir ou deixar de produzir tabaco.

De maneira geral, do ponto de vista da racionalidade, os agricultores especializados, diversificados, que substituíram e que abandonaram o cultivo do tabaco, apresentam características distintas em relação a suas decisões. Por exemplo, nos agricultores especializados, tanto do grupo com percepção negativa quanto com 
percepção positiva do cultivo do tabaco, os elementos estruturais estão mais presentes e as garantias do SIPT exercem maior influência sobre suas reações.

Todavia, há de se considerar que toda decisão envolve risco e fatores que escapam de nosso controle, como os ambientais, as estratégias e recursos, gerando incerteza. Por esses motivos, tomar uma decisão pode ser estressante (PEREIRA; FONSECA, 1997). Nesse sentido, há uma distinção em relação ao conflito cognitivo dos agricultores. Nos agricultores do grupo com percepção positiva, o conflito cognitivo é reduzido ou inexistente, já que suas reações exigem menor esforço de suas racionalidades, uma vez que se sentem amparados pelo SIPT. Nos agricultores com percepção negativa, o conflito cognitivo é maior, já que questionam as garantias do SIPT e não vislumbram alternativas para mudança da situação. A sensação de conflito é maior à medida que expressam passividade diante da possibilidade de mudar seus destinos.

\section{Gráfico 1. Elementos que constituem a estrutura da racionalidade dos agricultores}

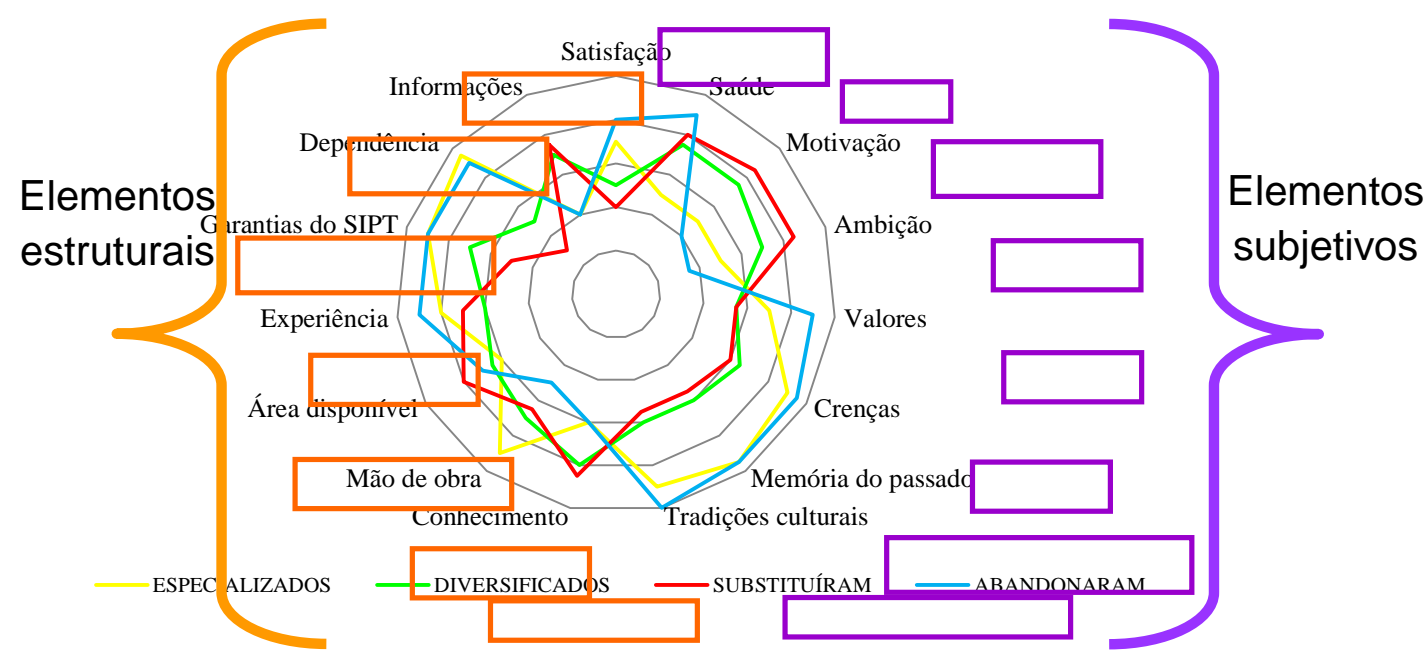

Fonte: Elaborado pelo autor a partir de dados do levantamento de campo (2013). Nota: Retângulos na cor laranja representam os elementos estruturais e na cor roxa os elementos subjetivos.

A presença e intensidade dos elementos estruturais e subjetivos podem representar limitações cognitivas, mas, considerando que os agentes são dotados de uma racionalidade limitada, a apreensão de todos os elementos em suas racionalidades é algo difícil, devido à 
racionalidade limitada. Assim sendo, os elementos presentes na racionalidade dos agricultores, apresentados na figura acima, reportamse à vida do agricultor, à comunidade onde está inserido, a um período de tempo e a uma sociedade.

É graças à relação dos elementos estruturais e subjetivos e à situação e objetivos dos agricultores que surgem conflitos cognitivos relacionados à decisão de produzir ou deixar de produzir tabaco. Assim posto, observa-se uma multiplicidade de comportamento em reação a este conflito, ou seja, é o nível ou a intensidade do conflito cognitivo entre a situação e seus objetivos que determinará sua reação a este conflito. Disso depreende-se que é a presença e a amplitude dos elementos estruturais e subjetivos que serão os responsáveis pela diversidade de reações dos agricultores: especializar, diversificar, substituir ou abandonar o cultivo do tabaco.

Diante dessas constatações, os dados permitem afirmar que os agricultores com percepção positiva da produção de tabaco atuam a partir de uma conduta guiada pelo reconhecimento de que esta atividade é a melhor alternativa para pequenos produtores. Em suas avaliações, eles consideram a relação custo/benefício dessa atividade como sendo boa, considerando suas situações socioeconômicas e estruturais. Desse modo, em seus depoimentos, internalizam os discursos das indústrias, ancorando suas decisões nas vantagens do SIPT.

A explicação para a decisão dos agricultores com percepção positiva da produção de tabaco são, sobretudo, os termos de referências relacionados aos elementos estruturais, ou seja, as garantias proporcionadas pelo SIPT, a relação de dependência econômica com a agroindústria e a ideia de que essa atividade é a melhor em termos de rendimento por hectare. Nesse ponto reside a racionalidade limitada dos agricultores, uma vez que, segundo os próprios discursos dos entrevistados, a renda obtida é insuficiente para satisfazer as necessidades básicas das famílias.

O discurso de que a produção de tabaco é a única ou a melhor fonte de renda para pequenos agricultores demonstra a limitação da racionalidade dos mesmos quando afirmam que tem anos em que, ao final da safra, sobra muito pouco ou quase nada de dinheiro, somente o suficiente para pagamento do seguro e do financiamento agrícola. É por 
ter uma racionalidade econômica incompleta (ABRAMOVAY, 1992) que os produtores de tabaco depositam tanta certeza no retorno financeiro dessa atividade.

No grupo de agricultores com percepção negativa do tabaco, na construção de suas racionalidades, destaca-se com maior expressão e influencia os elementos subjetivos. Para os agricultores desse grupo, embora a produção de tabaco seja importante em termos de reprodução familiar, a relação custo/benefício dessa atividade é tida como ruim, diante da qual os agricultores apresentam uma postura crítica. Assim, o ponto central da conduta dos agricultores desse grupo está nesta postura crítica em relação ao setor. Logo, suas reações são determinadas por uma rede mais complexa dos elementos estruturais e subjetivos que contraria as condutas tradicionais que defendem a ideia de que o tabaco é a "melhor" ou "única" alternativa para pequenos agricultores.

Essa proposição contribui na explicação da grande presença nesse grupo de agricultores das categorias que substituíram e diversificaram a produção de tabaco. Desse modo, essa postura mais crítica explica a maior diversidade de reação no sentido de buscar alternativas ao cultivo do tabaco. A reação no sentido de diversificar ou substituir a produção de tabaco intensifica-se a partir da descoberta de novas perspectivas, capaz de criarem alternativas que antes não eram vislumbradas pelos agricultores.

Advêm disso novas estratégias de ações no sentido de transformações produtivas, novas formas de produção e comercialização, construção de outros saberes e conhecimentos que contrariam o discurso dominante no setor. Cabe lembrar que condições desfavoráveis em termos de elementos estruturais podem inibir a influência de elementos subjetivos e vice-versa. Desse modo, conforme apontado por Lima et al. (2001) e por Lamarche (1983), o comportamento dos agricultores é resultado de suas necessidades atuais e futuras, mas considerando suas potencialidades e limitações na situação presente.

Dessa forma, os dados empíricos encontrados nesta pesquisa coadunam com os de Perondi et al. (2012, p. 694), ao afirmarem que a decisão sobre a atividade para substituir a produção de tabaco está relacionada "[...] as possibilidades financeiras e uma melhor qualidade 
de vida, determinada por uma atividade que oferece menor risco à saúde da família do produtor, com trabalho menos intenso e executado com menor penosidade [...]". A diversificação, vista como uma decisão deliberada, possui duas características essenciais: a possibilidade de buscar e praticar algo novo e a potencialidade de rompimento com os fatos estabelecidos historicamente.

Nesse sentido, a partir dos dados qualitativos da pesquisa, podese afirmar que as decisões dos agricultores em deixar de produzir tabaco estão relacionadas à busca por autonomia financeira e melhor qualidade de vida. Com exceção de um agricultor, que substituiu o cultivo do tabaco devido a suas terras terem sido infectadas por uma bactéria que impede o desenvolvimento da planta, todos os outros produtores que substituíram e diversificaram o cultivo do tabaco tentaram mais de uma atividade produtiva. Isso permite concluir que a diversificação é uma condição para a substituição do cultivo do tabaco.

Para Schneider (2010), a consolidação da diversificação depende de sua institucionalização e enraizamento nas estruturas cognitivas, mentais e culturais, tanto dos agricultores quanto da população em geral, incluídos os gestores públicos e instituições governamentais. Segundo o autor, a sustentabilidade do sistema está sujeita à possibilidade dos agentes estabelecerem formas de governança mantendo a capacidade de controle e regulação democráticos e participativos. Essa proposição é corroborada por Zylbersztajn (1995) que, ao referir-se aos modos de governança dos sistemas agroindustriais, constatou que eles são definidos a partir da interação entre as características das transações e do ambiente organizacional e institucional.

Tendo em vista que analisar a racionalidade de agricultores familiares produtores de tabaco é tarefa complexa, um ponto relevante para o presente estudo está exatamente na coexistência de racionalidades que envolvem elementos estruturais de ordem econômica, social, cultural e ambiental e a presença de um componente subjetivo dessa racionalidade. O componente subjetivo, por estar baseado, principalmente, em aspectos cognitivos dos agricultores (nos saberes e experiências individuais, produzidos pela experiência), funciona como limitante de suas racionalidades. 
Tendo isso em mente, os agricultores agem na busca de alternativas satisfatórias, o que aproxima os agricultores produtores de tabaco do VRP da concepção de homem administrativo. Ou seja, um indivíduo que toma decisões sem poder procurar todas as alternativas possíveis, sua motivação não está na procura do lucro máximo, mas no lucro adequado, não estão à procura do preço ótimo do tabaco, mas do preço razoável.

\section{CONSIDERAÇÕES FINAIS}

Constatou-se que as decisões dos agricultores em produzir ou deixar de produzir tabaco são tidas enquanto fruto de necessidades pessoais de reprodução da família ou reações às suas percepções em relação à atividade. Independentemente de qual seja a motivação, são resultados do esforço individual das famílias em construir ou determinar seus projetos futuros de vida. Desse modo, embora com perfis muito parecidos, é a presença e a intensidade dos elementos subjetivos e estruturais dos agricultores que irá refletir na maneira que criam o modelo da situação e, consequentemente, em suas reações a esse modelo. Esta constatação justifica os quatro tipos de comportamentos encontrados na pesquisa e podem ser tomadas como racionalidade de estratégia e conduta nos agricultores especializados, diversificados, que substituíram e que abandonaram o cultivo do tabaco.

O reconhecimento de que por si só a percepção negativa do cultivo do tabaco não é suficiente para desencadear reações em direção à diversificação, substituição ou abandono da atividade, traz à tona a importância dos elementos estruturais e subjetivos dos entrevistados. Assim, as mudanças que são desencadeadas a partir da presença e da intensidade dos elementos estruturais e subjetivos ocorrem de forma gradual, em etapas, onde o intuito dos agricultores é buscar alternativas satisfatórias.

Constatou-se que a racionalidade limitada está presente entre os agricultores e opera à medida que os mesmos possuem limites em suas capacidades cognitivas, detêm informações incompletas e são desprovidos de recursos que maximizem a busca de informações e alternativas viáveis ao cultivo do tabaco. Sendo assim, a racionalidade da decisão em produzir ou deixar de produzir tabaco está intimamente 
associada às certezas do SIPT, à incerteza da comercialização de outras culturas e nos esforços individuais na busca de alternativas. Optar pelo cultivo do tabaco produz certo conforto cognitivo à medida que minimiza a racionalidade limitada, enquanto deixar de produzir constitui um desconforto cognitivo já que exige mais da racionalidade limitada dos agricultores. É a associação dos elementos estruturais e subjetivos dos agricultores, somados a um ambiente institucional favorável que irão determinar a profundidade da mudança.

\section{REFERÊNCIAS}

ABRAMOVAY, R. Paradigmas do capitalismo agrário em questão. 2. ed. São Paulo: Hucitec/Edunicamp, 1992. 275 p.

Desenvolvimento e instituições: a importância da visão histórica. In: ARBIX, Glauco; ZILBOVICIUS, Mauro; ABRAMOVAY, Ricardo. (Org.). Razões e ficções do desenvolvimento. São Paulo: Edunesp/Edusp, 2001, p. 149-163.

ANDRADE, J. J. O processo de tomada de decisão dos produtores rurais no município de Sant'Ana do Livramento/RS. 2010.288 f. Tese (Doutorado em Desenvolvimento Rural), Universidade Federal do Rio Grande do Sul, 2010. Disponível em $<$ http://www.ufrgs.br/pgdr/dissertacoes_teses/arquivos/doutorado/PG DR_D_028_JEANICE_ANDRADE.pdf > . Acesso em: 08 out. 2013.

BAERT, P. Algumas limitações das explicações da escolha racional na ciência política e na sociologia. In: Revista Brasileira de Ciências Sociais. Fev. 1997, vol.12, n. 35. Disponível em:

$<$ http: / www.scielo.br/scielo.php?script=sci_arttext\&pid=S010269091997000300005 > . Acesso em: 18 out. 2013.

BARDIN, L. Análise de conteúdo. São Paulo: Edições 70, 2011.

CAMPOS, C. J. G. Método de análise de conteúdo: ferramenta para a análise de dados qualitativos no campo da saúde. Revista Brasileira de Enfermagem, v. 57, n. 5, p. 611-614, 2004. 
CANZIANI, J. R. F. Assessoria administrativa a produtores rurais no Brasil. 2001. 224 f. Tese (Doutorado em Ciências, área de concentração economia aplicada). Universidade de São Paulo, 2001. Disponível em: $<$ http://www.teses.usp.br/teses/disponiveis/11/11132/tde28042004-105912/pt-br.php>. Acesso em: 13 dez. 2013.

CARVALHO, B. S. A Escolha Racional como teoria social e política: uma interpretação crítica. Rio de Janeiro: Topbooks, 2008, 281 p.

CHIAVENATO, I. Introdução à teoria geral da administração. 6 ed. Rio de Janeiro: Campus, 2000, 700 p.

ETGES, V. E. Sujeição e resistência: os camponeses gaúchos e a indústria do fumo. 1989. 246 f. Dissertação (Mestrado em geografia humana), Universidade de São Paulo, São Paulo, 1989.

FERREIRA, M. A. F. Os produtores de fumo da Bacia do Rio Pardinho: o cotidiano subalterno e a difícil mudança. In: ETGES, V. E.; FERREIRA, M. A. F. (Org.). A produção do tabaco: impacto no ecossistema e na saúde humana na Região de Santa Cruz do Sul/RS. Santa Cruz do Sul: EDUNISC, 2006. p. $x x-x x$.

FOOD AND AGRICULTURE ORGANIZATION OF THE UNITED NATIONS FAO. Issues in the global tobacco economy - selected case studies. Roma, 2003. Disponível em:

<http://www.fao.org/docrep/006/y4997e/y4997e0k.htm\#TopOfPage>. Acesso em: 7 out. 2013.

INSTITUTO BRASILEIRO DE GEOGRAFIA E ESTATÍSTICA - IBGE. Índice dos mapas estatísticos. Rio de Janeiro: IBGE, 2006. 777 p. Disponível em: $<\mathrm{ftp}$ //geoftp.ibge.gov.br/mapas_estatisticos/censo_2010/mapa_munic ipal_estatistico/>. Acesso em: 3 mar. 2014.

LAMARCHE, H. A agricultura familiar: comparação internacional. Campinas, SP: Editora da UNICAMP, 1993. 336 p. 
LIMA, A. P. et al. Administração da unidade de produção familiar: modalidades de trabalho com agricultores. $2^{\text {a }}$ ed. Ijuí: UNIJUí, 2001, 221 p.

MARCH, J. G.; SIMON, H. A. Teoria das organizações. Rio de Janeiro: FGV, 2. ed. 1970, $353 \mathrm{p}$.

MAXIMIANO, A. C. A. Teoria geral da administração: da revolução urbana à revolução digital. 6. ed. São Paulo: Atlas, 2007, 491 p.

NEVES, N. Lavoura dourada: a saga dos produtores de tabaco do Sul do Brasil. São Paulo: Évora, 2010, 176 p.

NORTH, D. Custos de transação, instituições e desempenho econômico. 3 ed. Rio de Janeiro: Instituto Liberal, 1994. 38 p.

PEREIRA, M. J. L. B.; FONSECA, J. G. M. Faces da decisão: as mudanças de paradigmas e o poder da decisão. São Paulo: Makron Books, 1997. p. 275.

PERONDI, M. A. et al. Prospeç̧ão de meios de vida alternativos ao cultivo do tabaco no Sudoeste do Paraná. Cadernos de Ciência \& Tecnologia, Brasília, v. 28, p. 675-695, 2012.

PRIEB, R. I. P. Pluriatividade na produção familiar fumageira. Santa Cruz do Sul: EDUNISC, 2005, 195 p.

RUDNICKI, Carlise Porto Schneider. As relações de confiança no sistema integrado de producão do tabaco (SIPT) no Rio Grande do Sul/Brasil. 2012. 198 f. Tese (Doutorado em Desenvolvimento Rural), Universidade Federal do Rio Grande do Sul, 2010. Disponível em:

<http://www.lume.ufrgs.br/bitstream/handle/10183/54520/00085639 5. pdf? sequence $=1>$ Acesso em: 1 dez. 2013.

SCHEJTMAN, A.; BERDEGUÉ, J. A. Desarrollo territorial rural. Santiago: RIMISP, 2004. 
SCHNEIDER, S. Reflexões sobre diversidade e diversificação: agricultura, formas familiares e desenvolvimento rural. Ruris, Campinas, v. 4, p. 88$131,2010$.

A abordagem territorial do desenvolvimento rural e suas articulações externas. Sociologias, v. 6, n. 11, p. 88-125, 2004.

SEN, A. K. Sobre ética e economia. São Paulo: Companhia das letras, 1999, $143 \mathrm{p}$.

SILVA, L. X. Análise do complexo agroindustrial fumageiro sul-brasileiro sob o enfoque da Economia dos Custos de Transação. 2002. 279 f. Tese (Doutorado em Economia), Faculdade de Economia, Universidade Federal do Rio Grande do Sul, 2002. Disponível em:

$<$ http://www.ufrgs.br/pgdr/arquivos/629.pdf>. Acesso em: 23 set. 2013.

et al. Descrição e análise do perfil socioeconômico das áreas e dos produtores de fumo em folha no Sul e no Nordeste do Brasil: um estudo baseado nos resultados do censo agropecuário 2006. (Relatório de pesquisa). Brasília, 2013. Disponível em:

<http://www.ufrgs.br/pgdr/arquivos/resultpesq/2.pdf >. Acesso em: 2 dez. 2013.

SILVEIRA, R. L. L. Complexo agroindustrial do fumo e território: a formação do espaço urbano e regional no Vale do Rio Pardo-RS. 2007. 578 f. Tese (Doutorado em Geografia), Universidade Federal de Santa Catarina. 2007. Disponível em: $<$ http://btd.unisc.br/Teses/RogerioSilveira.pdf>. Acesso em: 25 nov. 2013.

SIMON, H. A. Comportamento administrativo: estudo dos processos decisórios nas organizações administrativas. 2.ed. Rio de Janeiro: Fundação Getúlio Vargas, 1965, 311 p.

A capacidade de decisão e de liderança. 2.ed. Rio de Janeiro: Fundo de Cultura, 1972, 79 p. 
SMITH, A. Riqueza das nações. São Paulo: Folha de São Paulo, 2010. 423 p.

WANDERLEY, M. N. B. Agricultura familiar e campesinato: rupturas e continuidade. In: TEDESCO, João Carlos (Org.). Agricultura familiar: realidades e perspectivas. 2. ed. Passo Fundo: EDIUPF, p. 23-56, 1999.

WILLIAMSON, O. Las instituciones económicas del capitalismo. México: Fondo de Cultura Economica, 1985, 434 p.

ZOTTI, C. F. Meios de vida alternativos a cultura do tabaco nos municípios de Capanema e Planalto - PR. 2010. 128 f. Dissertação (Mestrado em Desenvolvimento Rural), Faculdade de Economia, Universidade Federal do Rio Grande do Sul, 2010. Disponível em: <http://www.lume.ufrgs.br/bitstream/handle/10183/36381/00081709 5.pdf? sequence $=1>$. Acesso em: 11 out. 2013.

ZYLBERSZTAJN, D. Estruturas de governança e coordenação do agribusiness: uma aplicação da nova economia das instituições. 1995. 238f. Tese (Doutorado em Economia), Universidade de São Paulo, São Paulo, 1995, Estados Unidos, 1995. Disponível em:

$<$ http://pensa.org.br/wpcontent/uploads / $2011 / 10$ /Estruturas_de_governanca_e_coordenacao_d o_agribusiness_uma_aplicacao_da_nova_economia_das_instituicoes_199 5.pdf >. Acesso em: 13 nov. 2015.

Submetido em 13/07/2014

Aprovado em $06 / 11 / 2015$

Sobre os autores

Marcelo Moraes de Andrade

Bacharel em Administração, Mestre em Desenvolvimento Rural/PGDR, Doutorando em Ciências Ambientais/UFOPA/PPGSND.

Endereço: Av. Marechal Rondon, 2370. 68040255 - Santarém - PA - Brasil.

E-mail:mllblues@yahoo.com.br

Leonardo Xavier da Silva 
Economista, Professor nos Programas DRI/ Desenvolvimento Rural - PGDR e Agronegócios - PPGA.

Endereço: Avenida João Pessoa, 31, Centro. 90040-000 - Porto Alegre - RS - Brasil.

E-mail: leonardo.xavier@ufrgs.br 